Divergence of Fbxl4

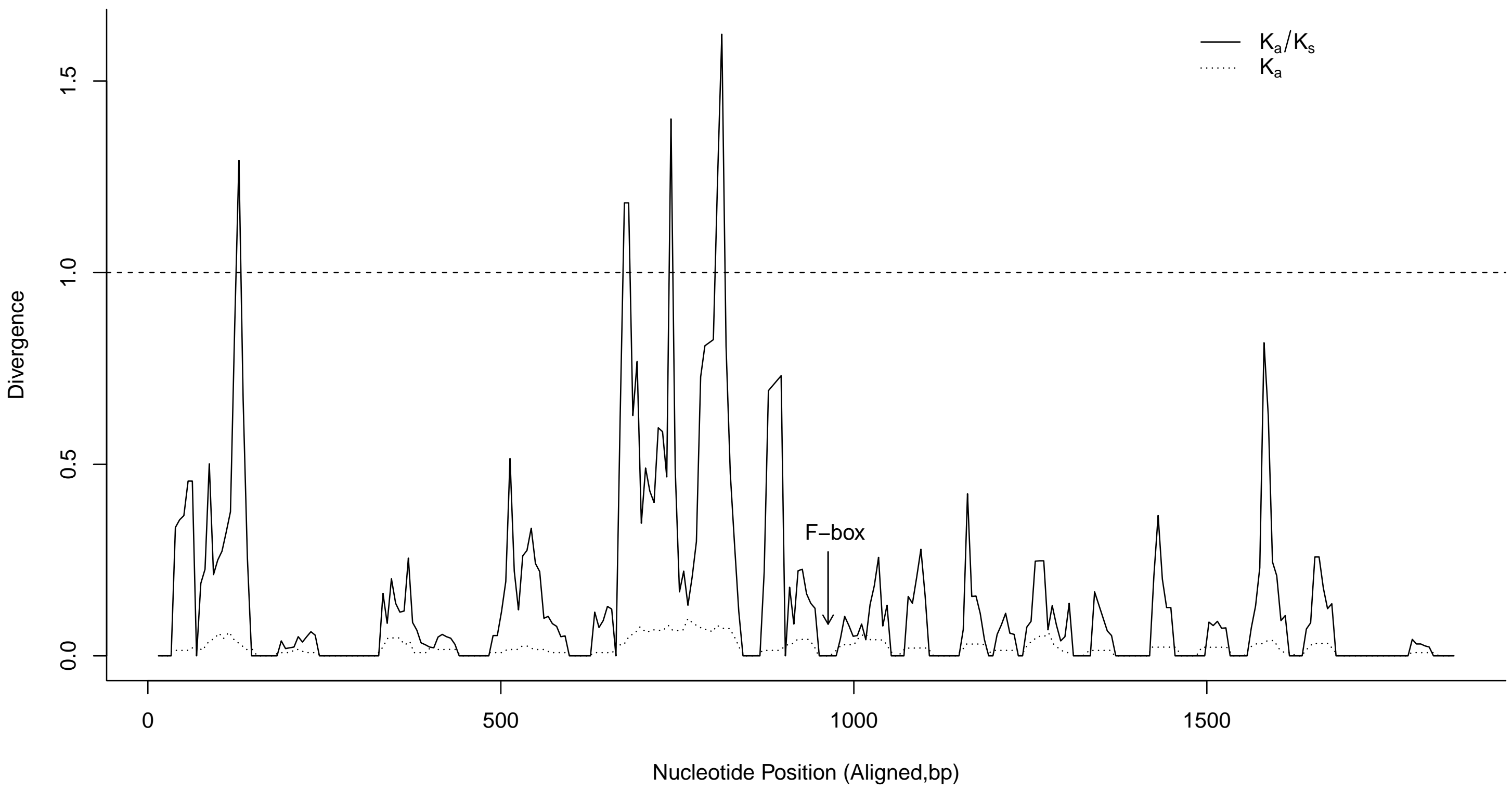




\section{Divergence of FbxI18}

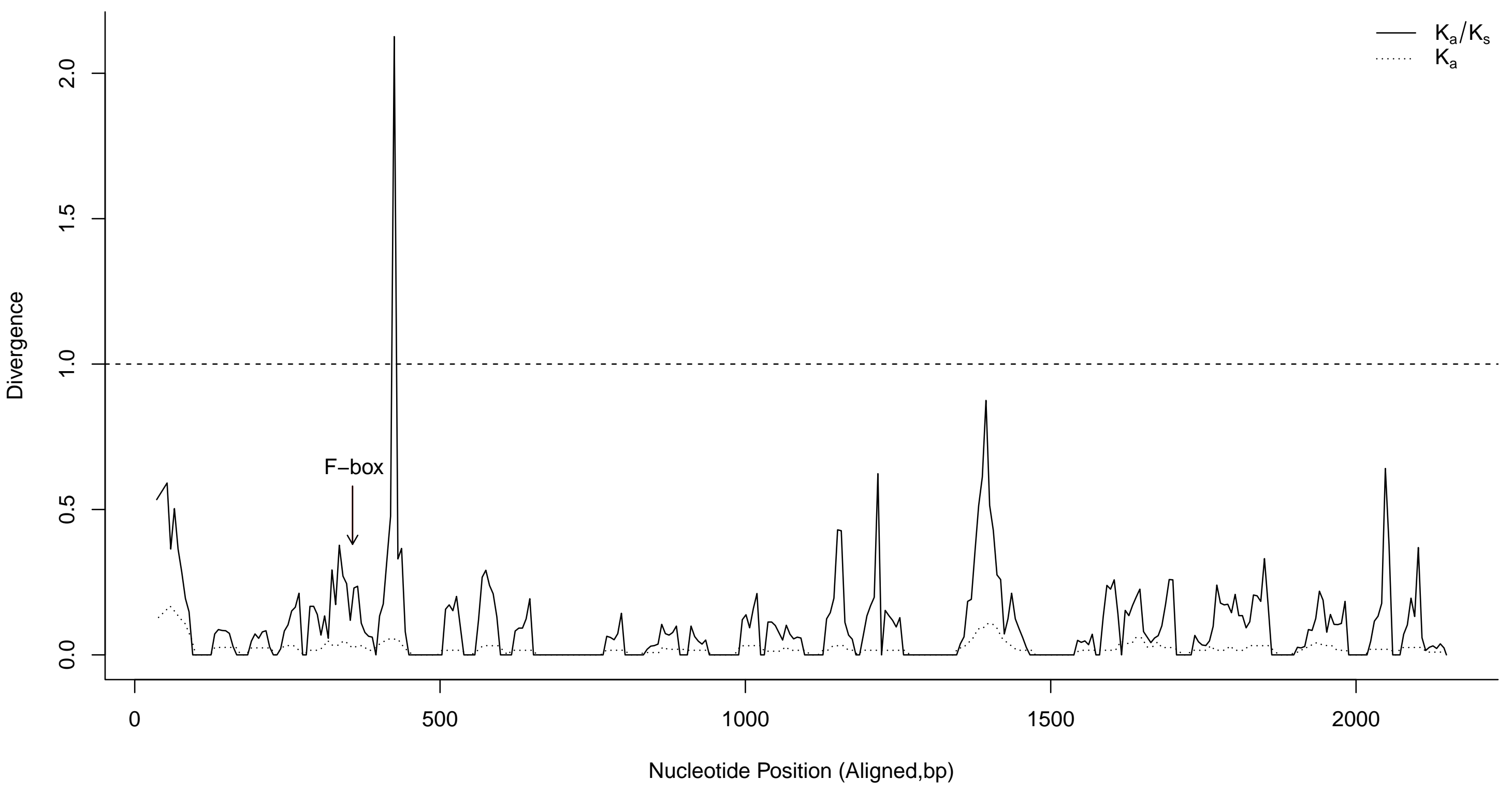




\section{Divergence of Fbxo6}

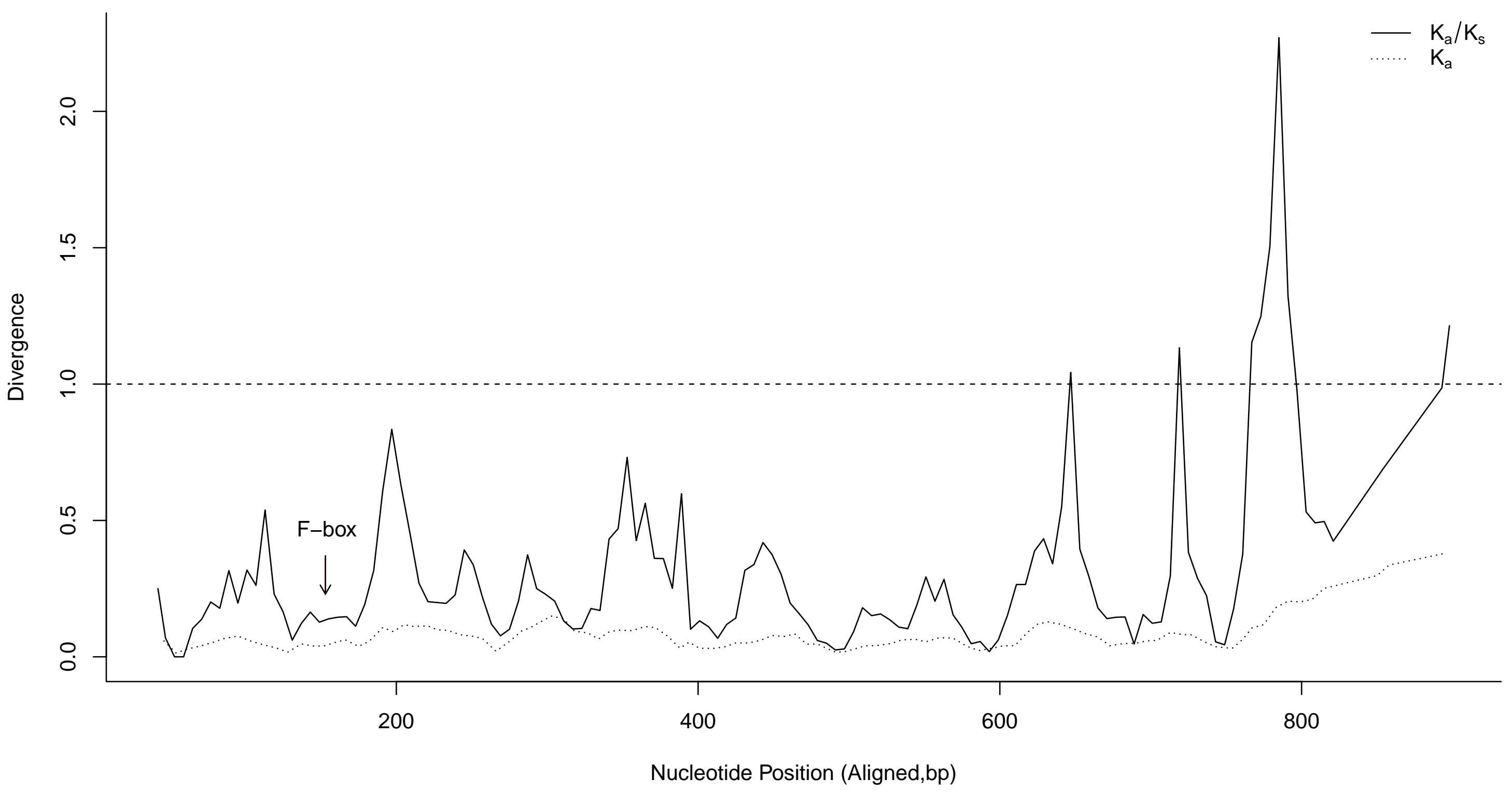


Divergence of Fbxo33

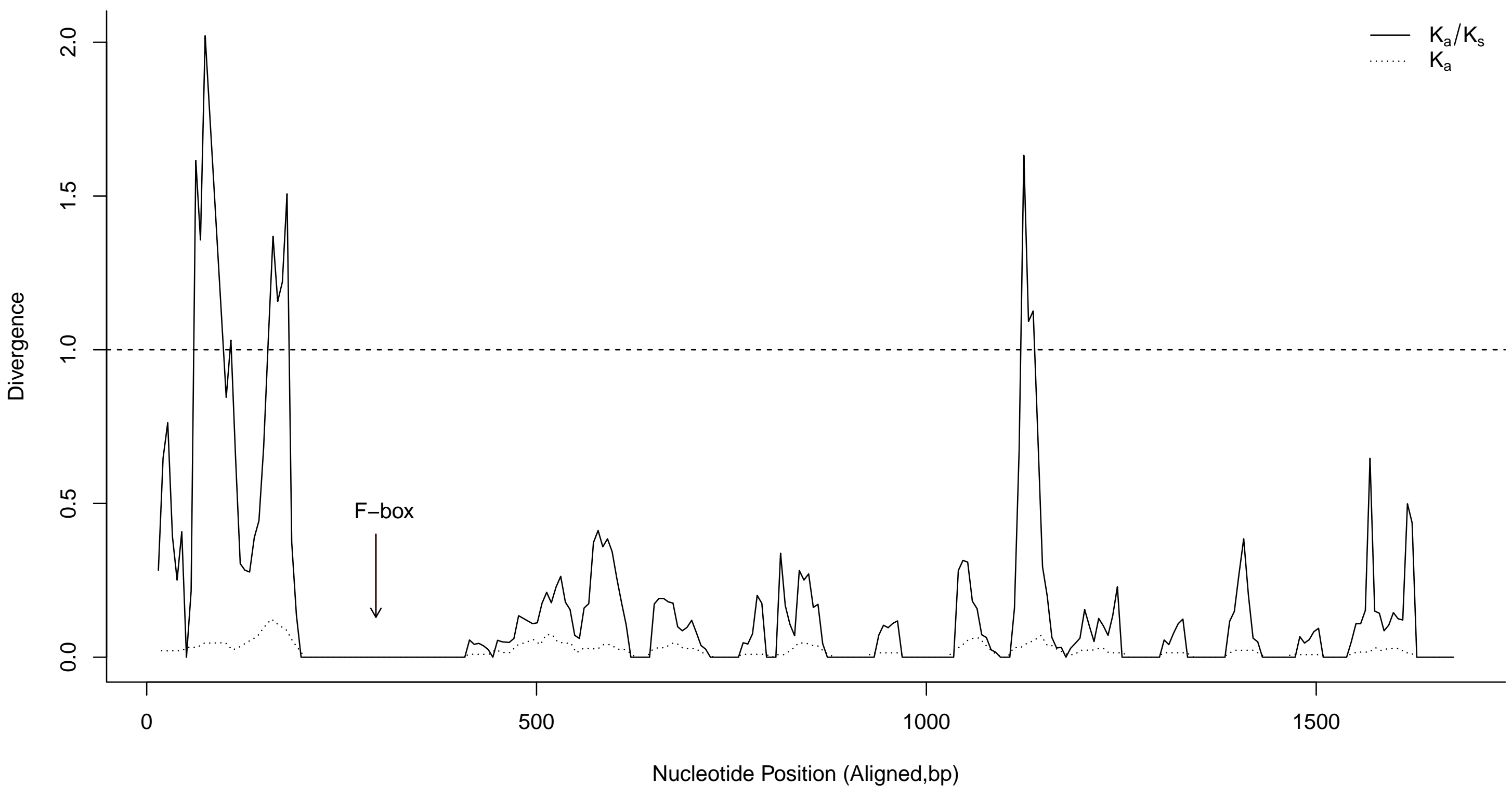




\section{Divergence of Fbxo38}

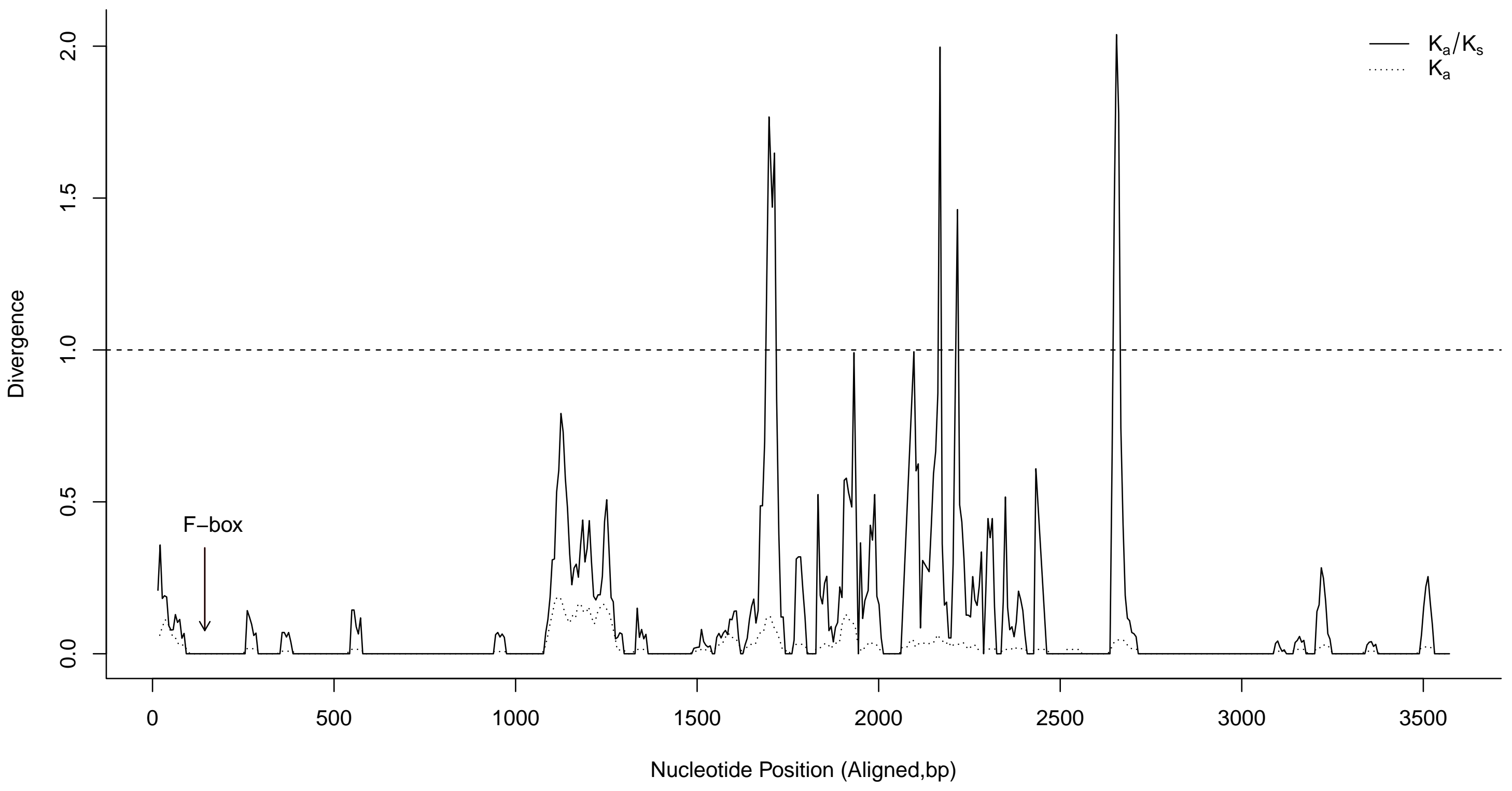




\section{Divergence of Fbxo18}

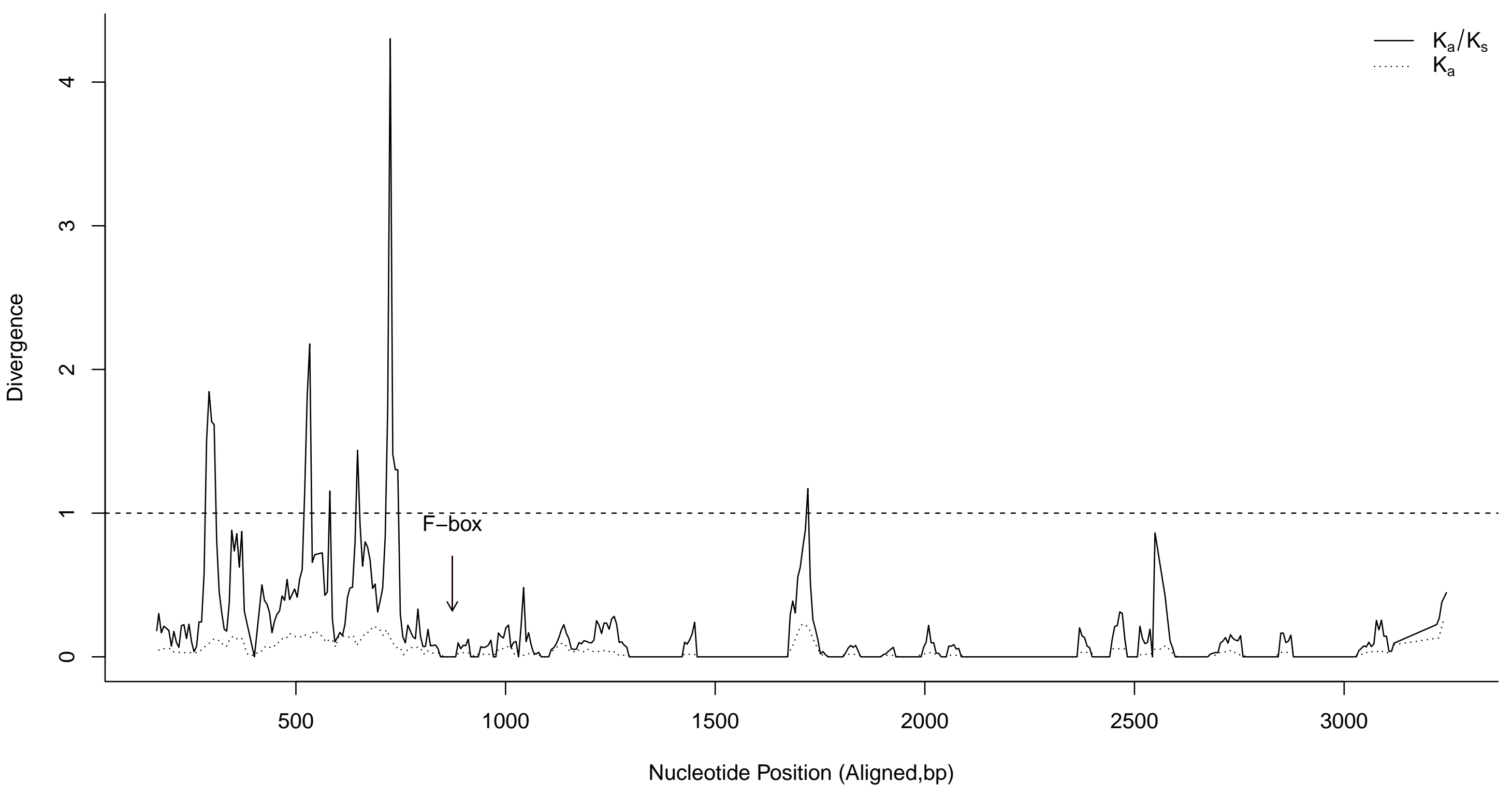




\section{Divergence of Fbxo30}

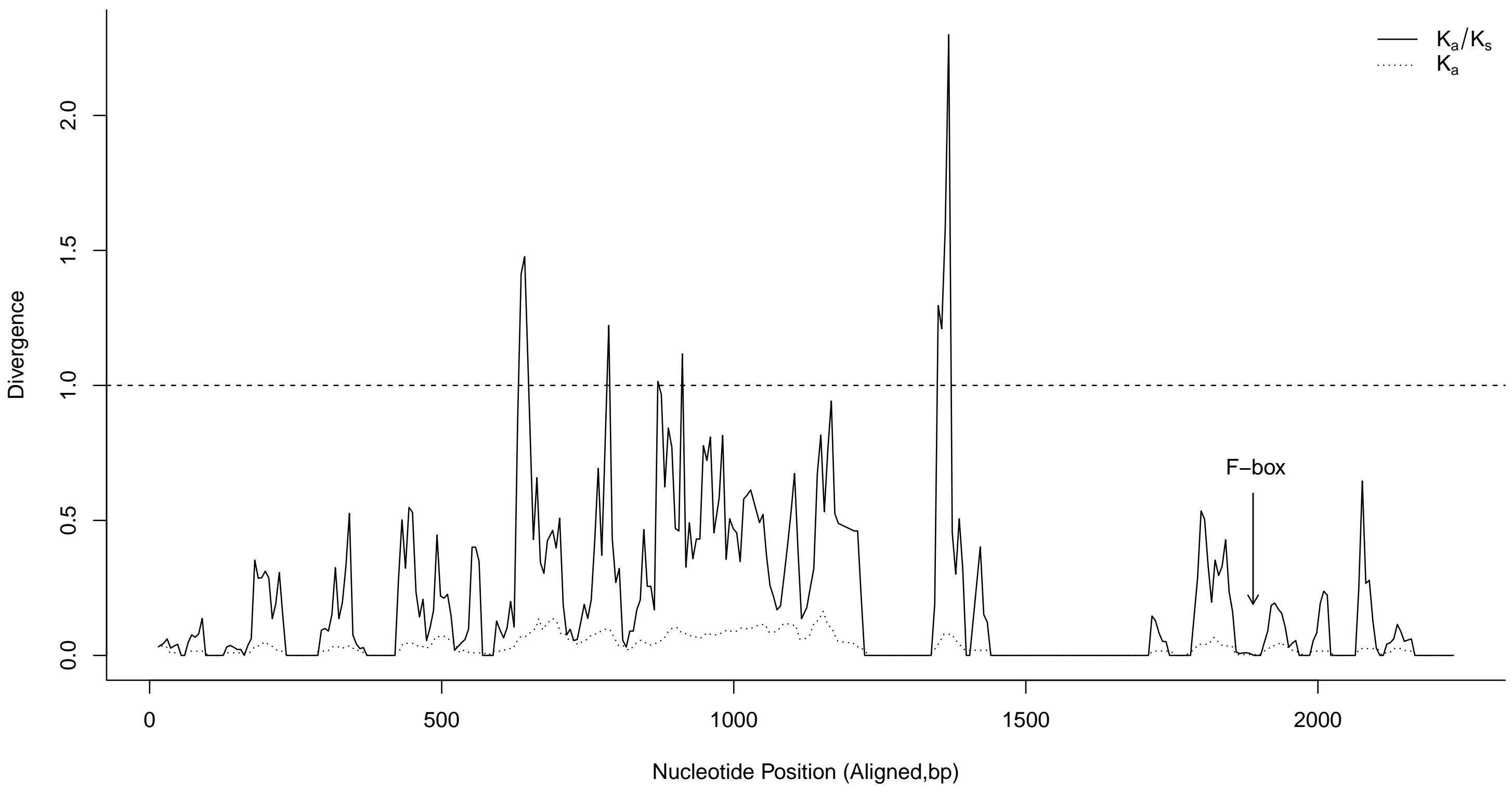




\section{Divergence of Fbxo34}

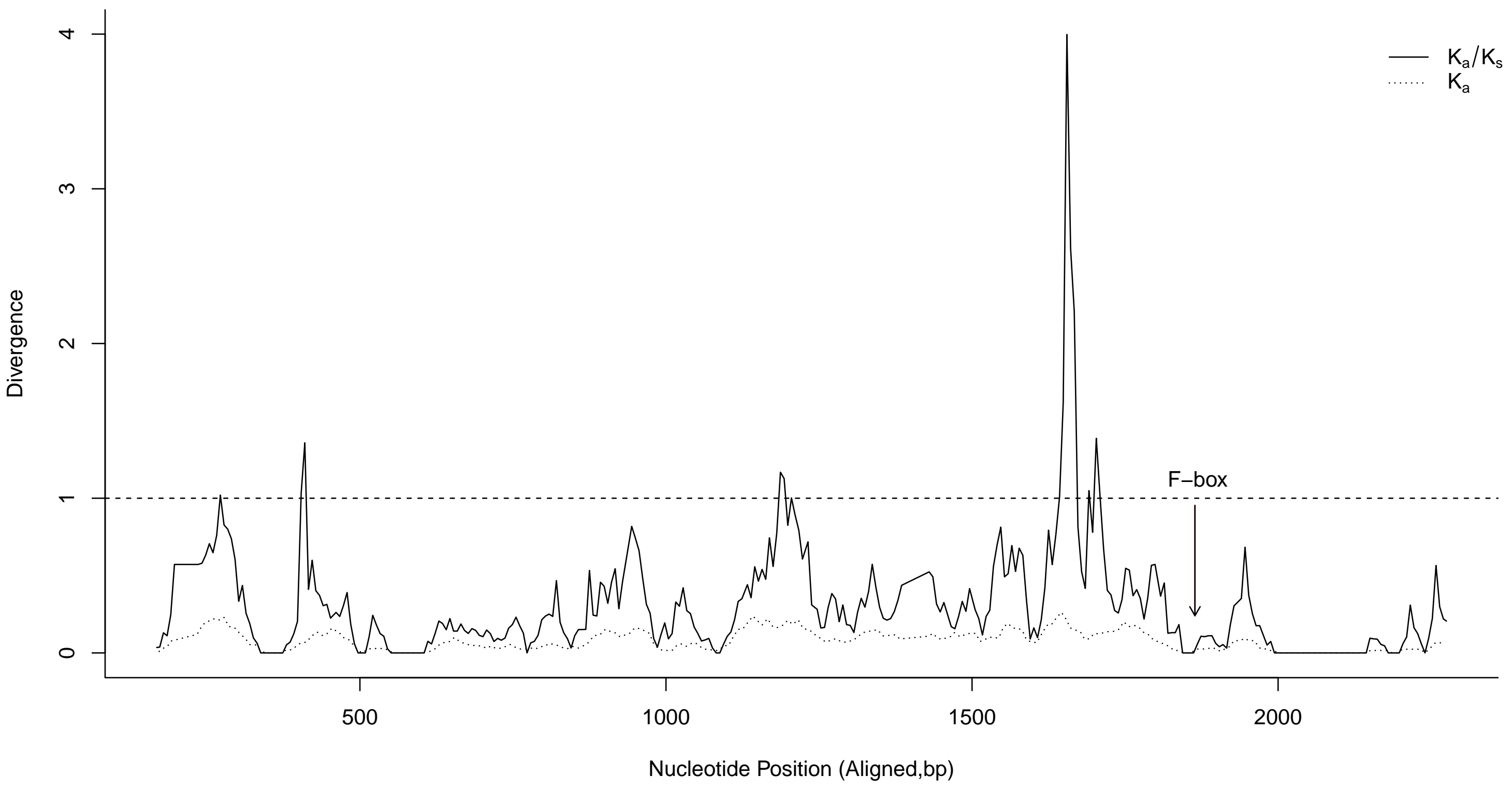


Divergence of Fbxo40

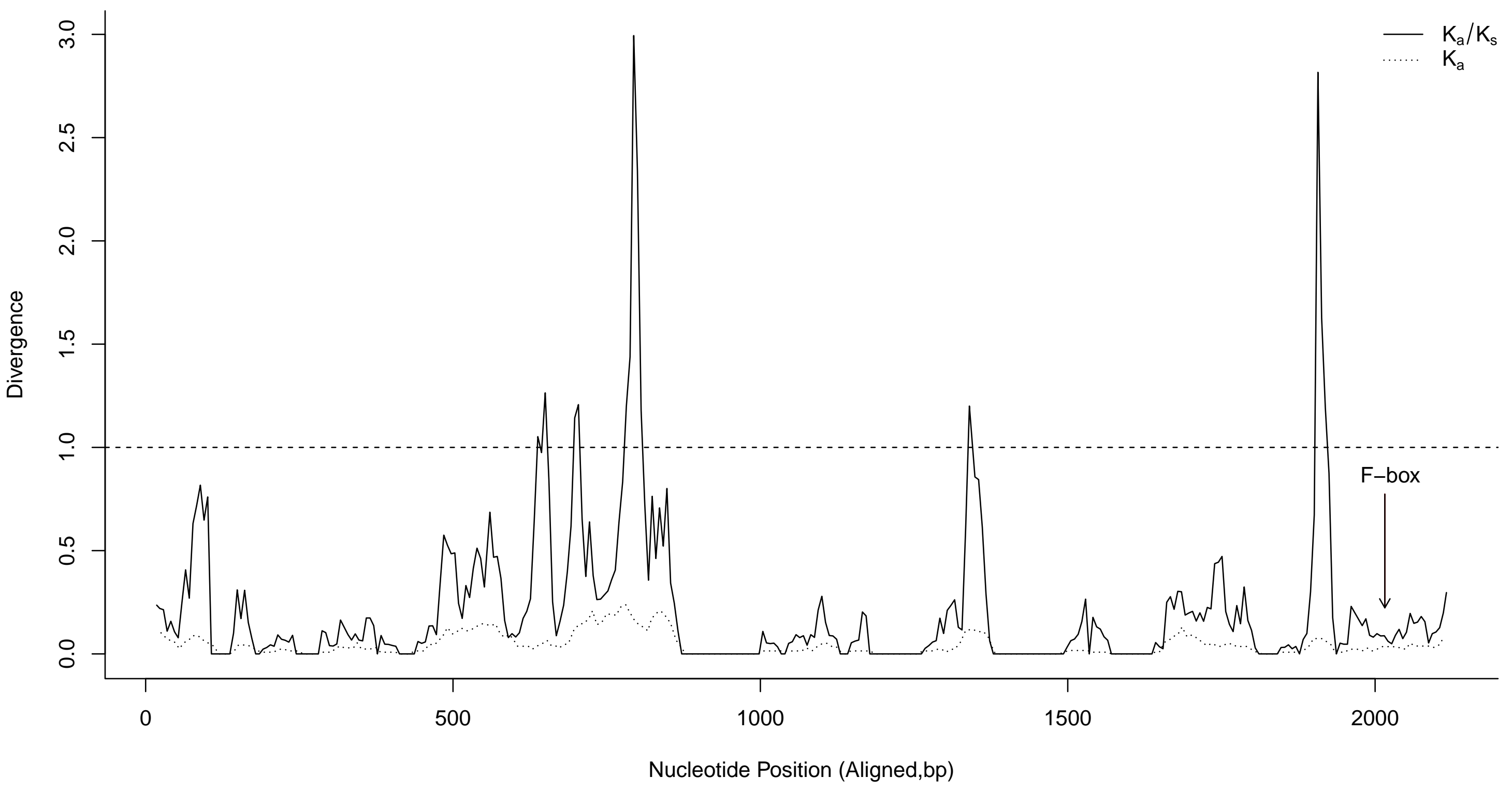




\section{Divergence of Fbxw9}

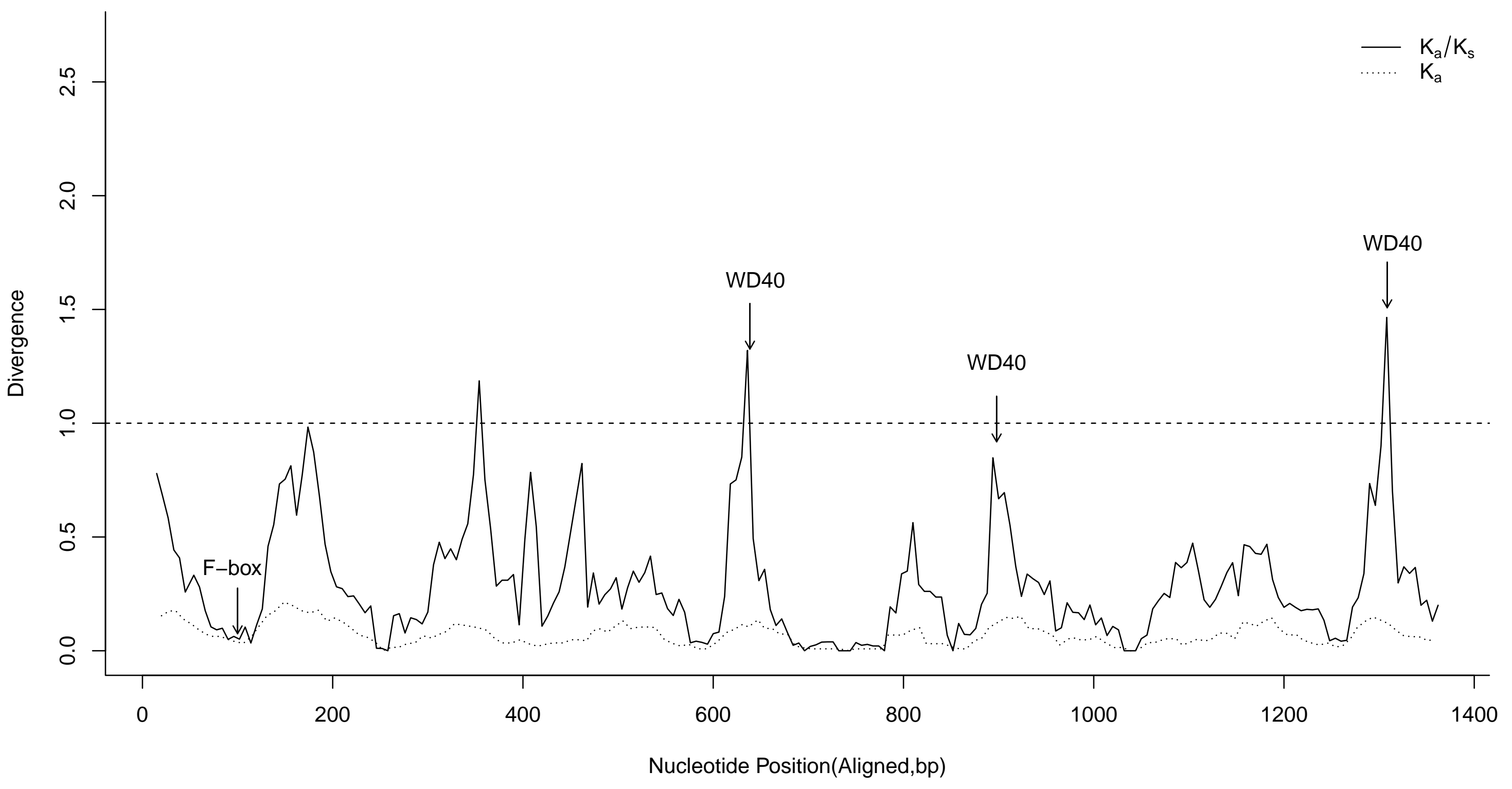




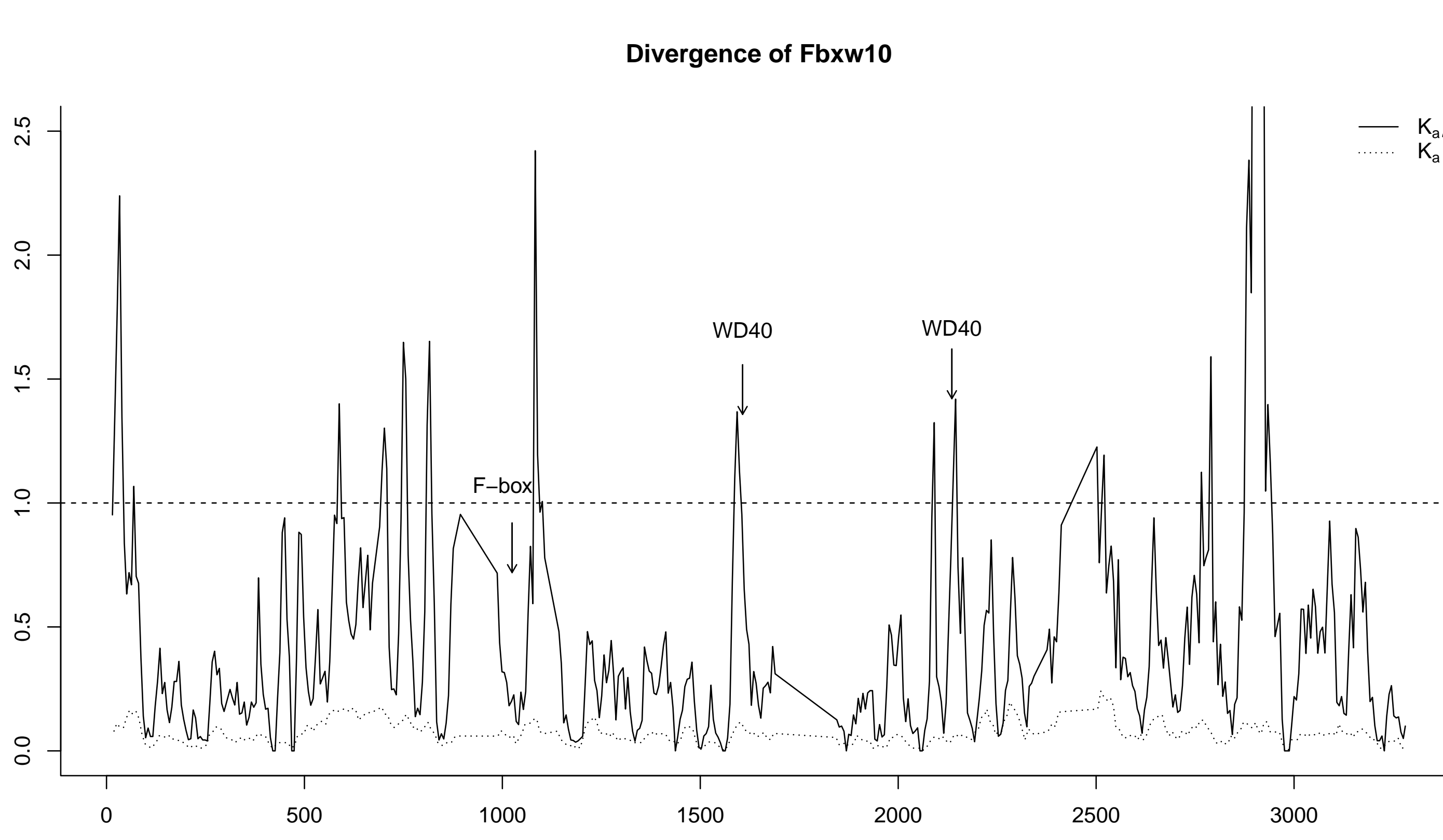




\section{Divergence of FbxI14}

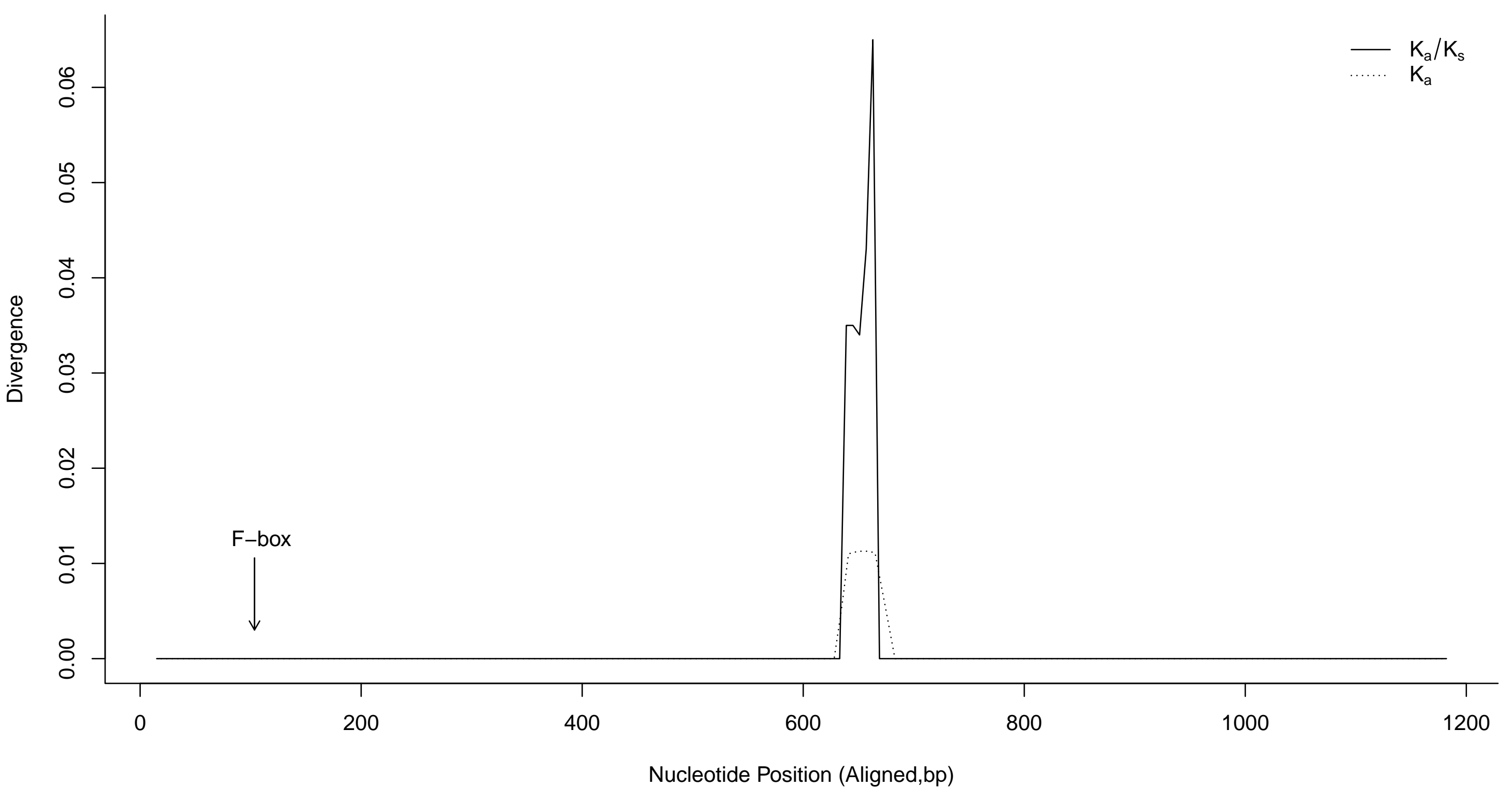




\section{Divergence of Fbxl16}

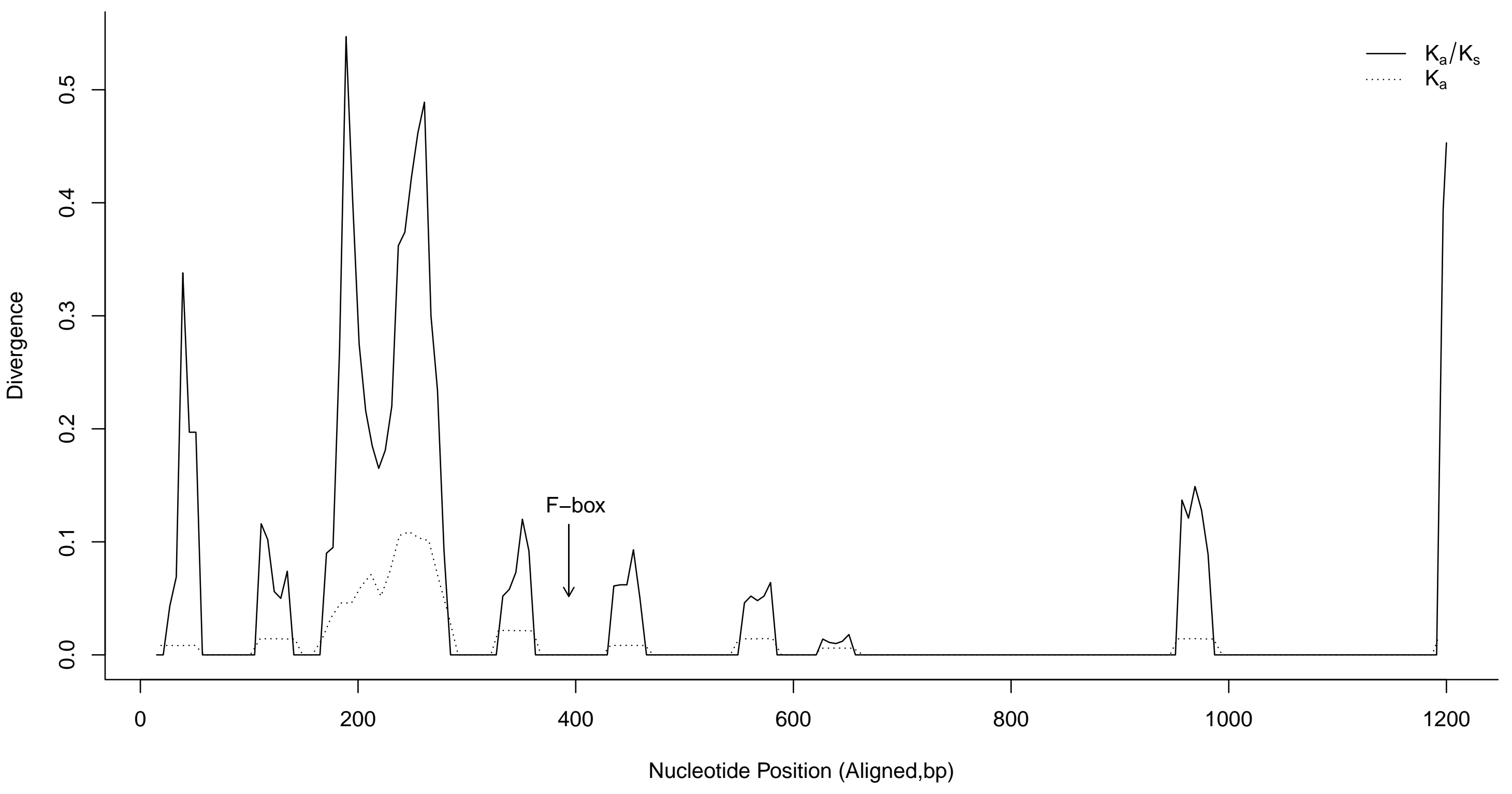




\section{Divergence of Fbxl17}

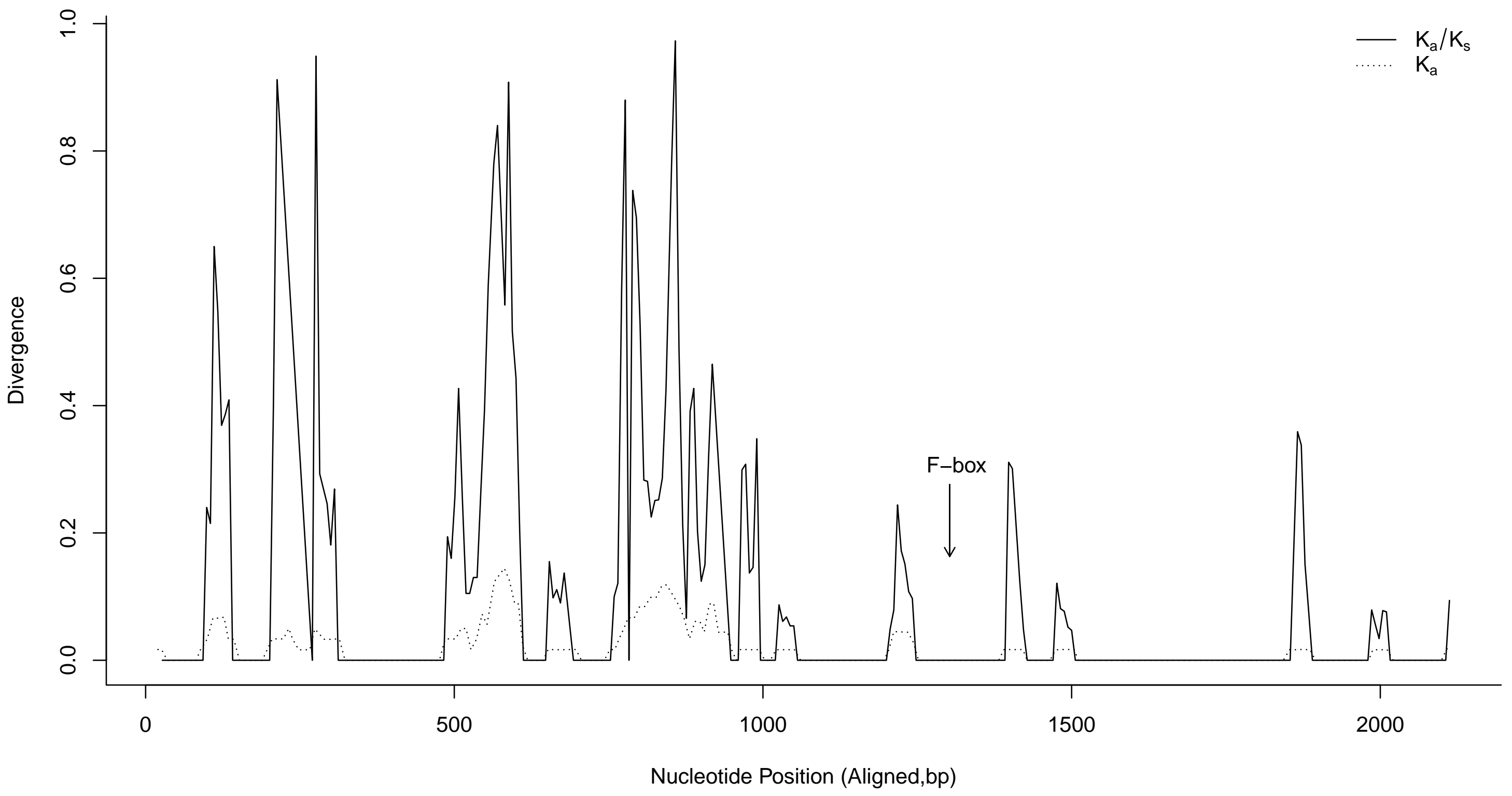




\section{Divergence of Fbxl2}

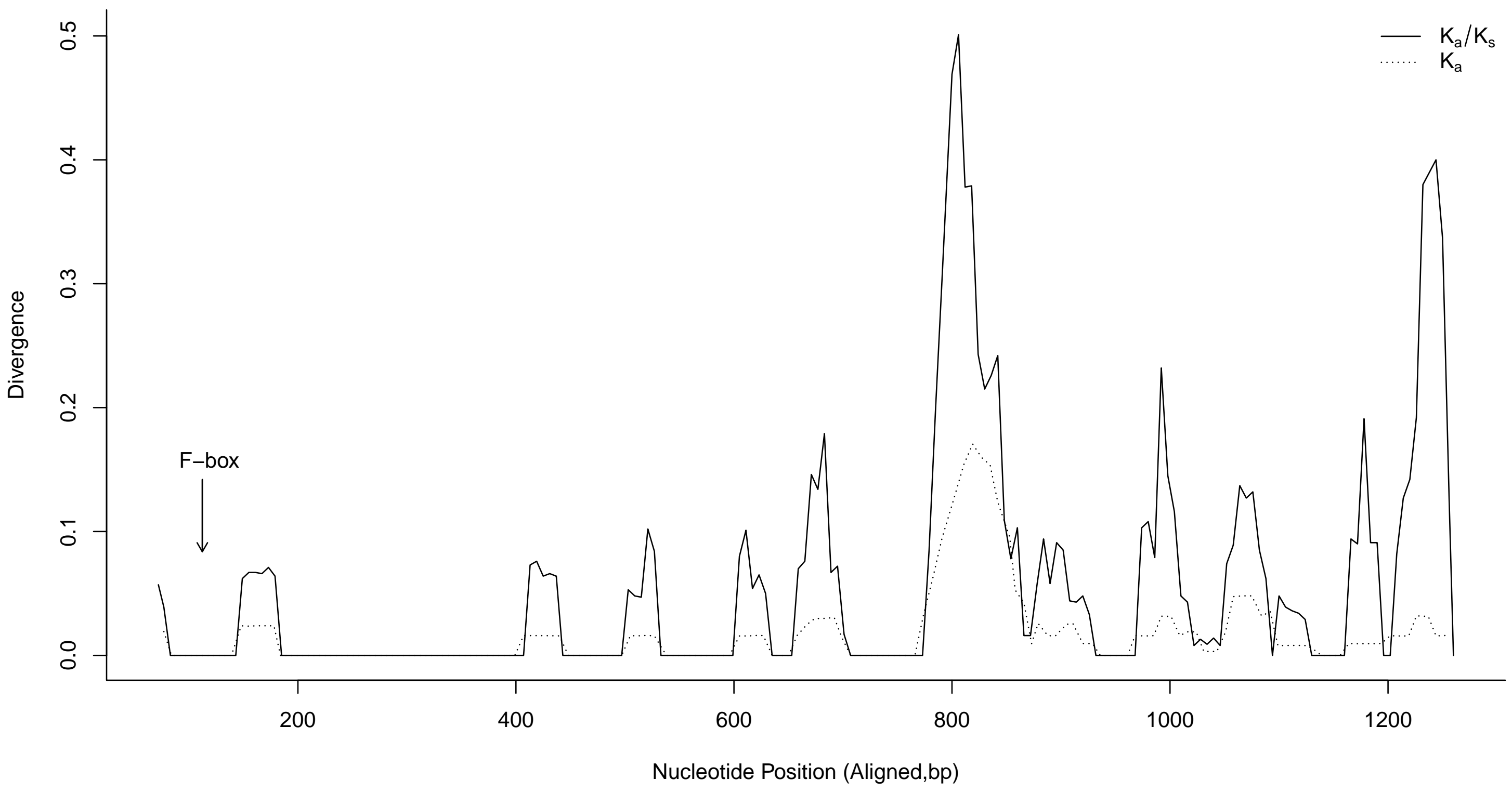


Divergence of FbxI6

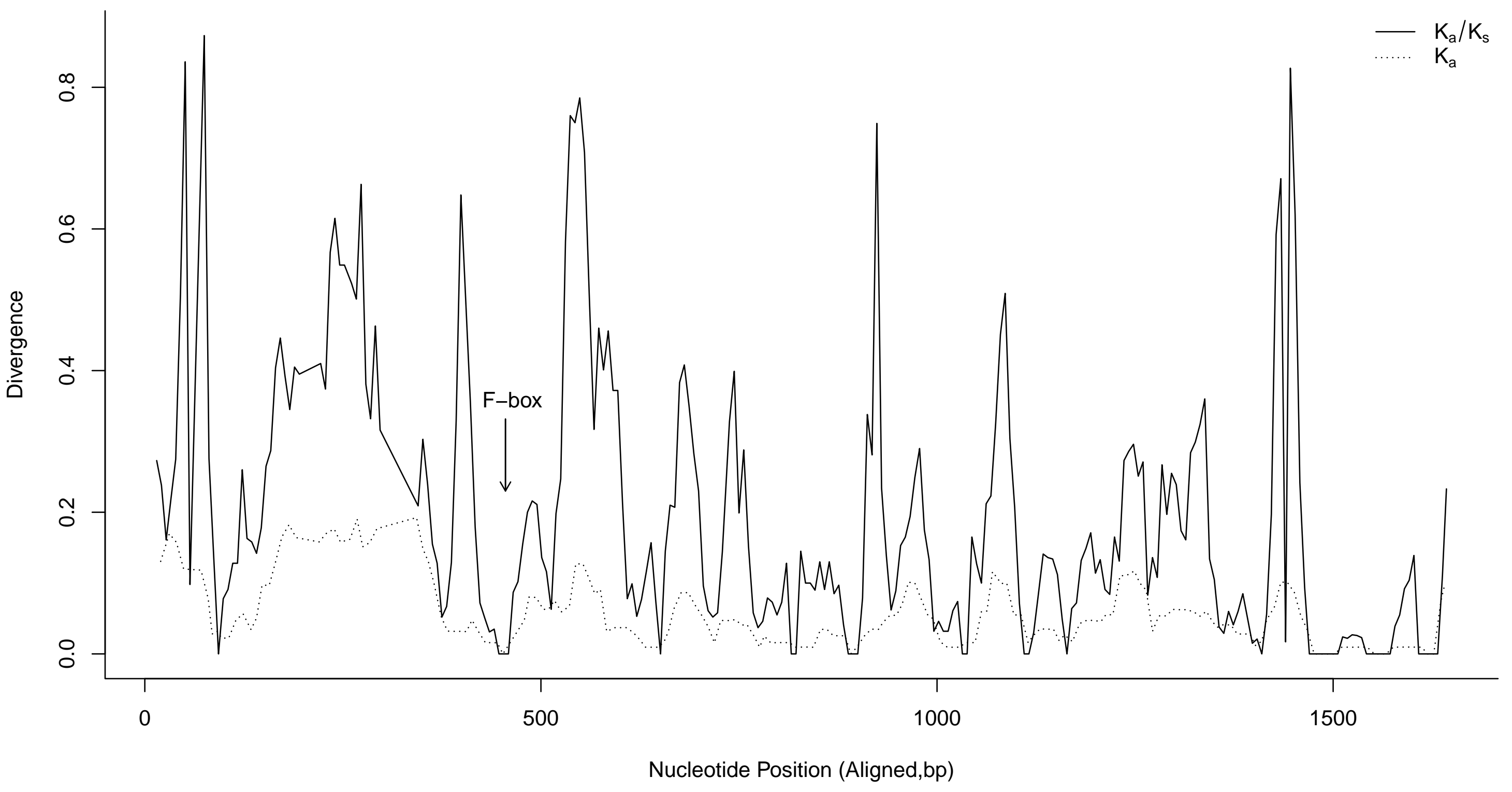




\section{Divergence of Fbxl7}

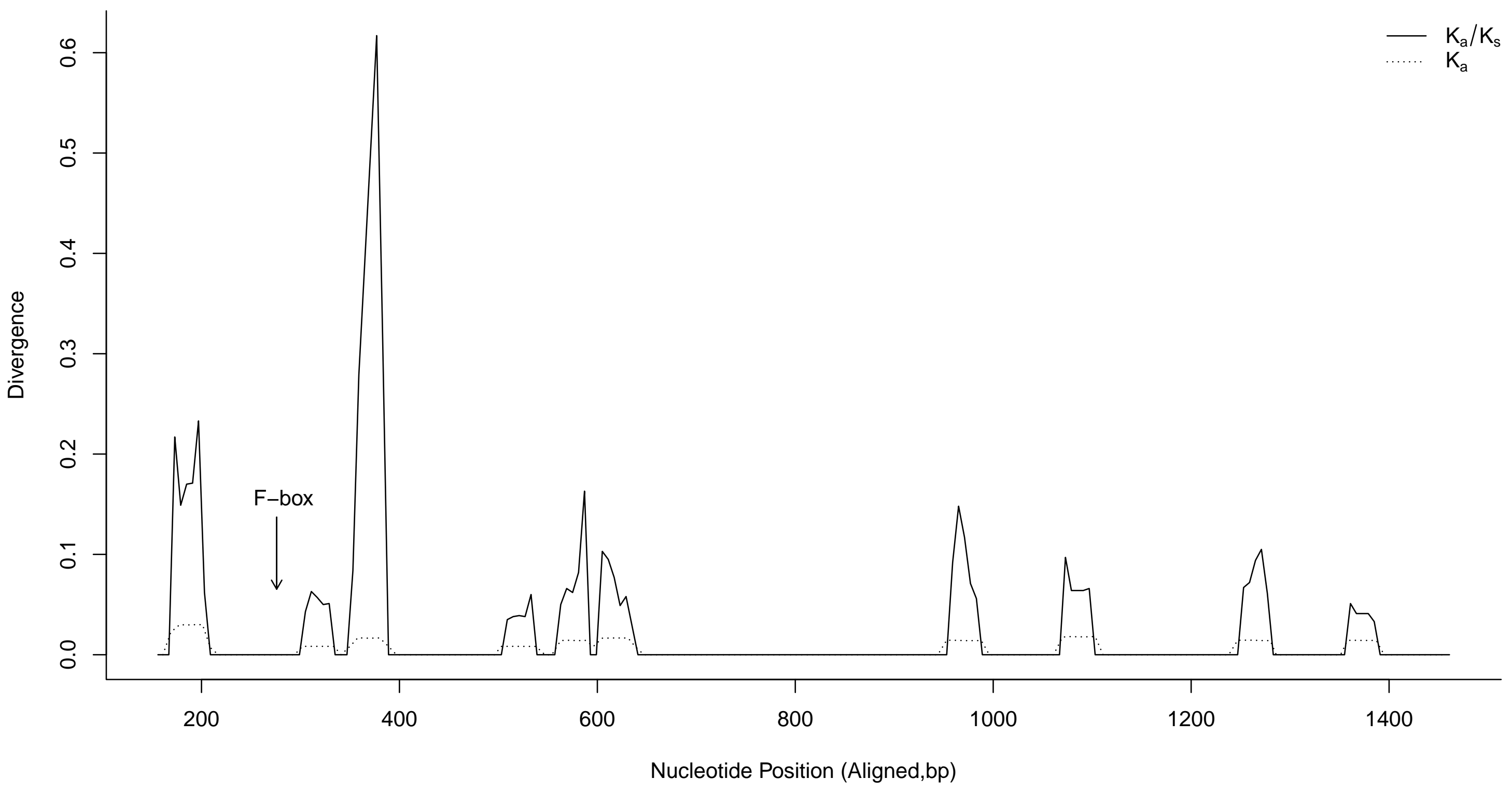


Divergence of Fbxo10

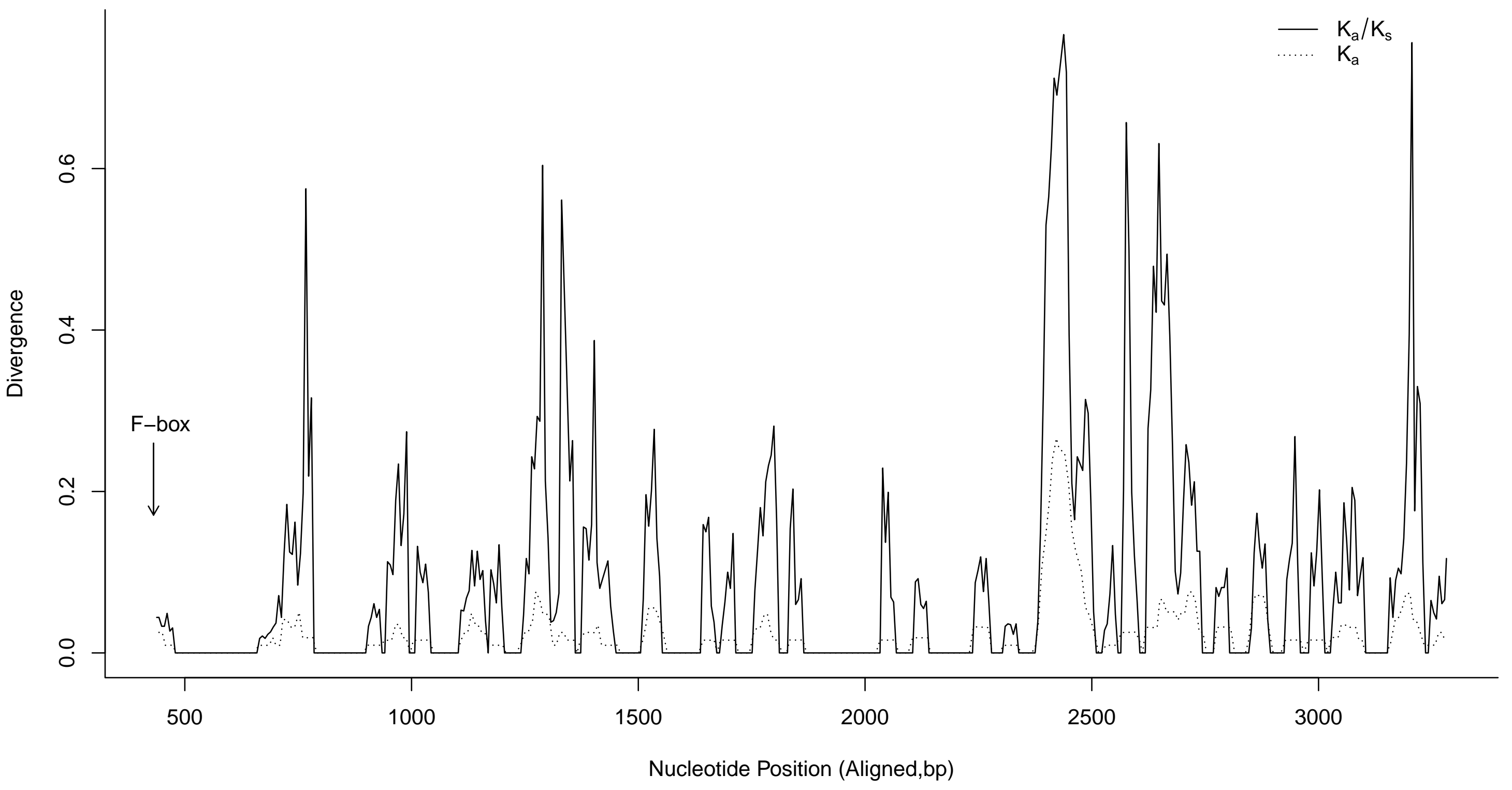




\section{Divergence of Fbxo17}

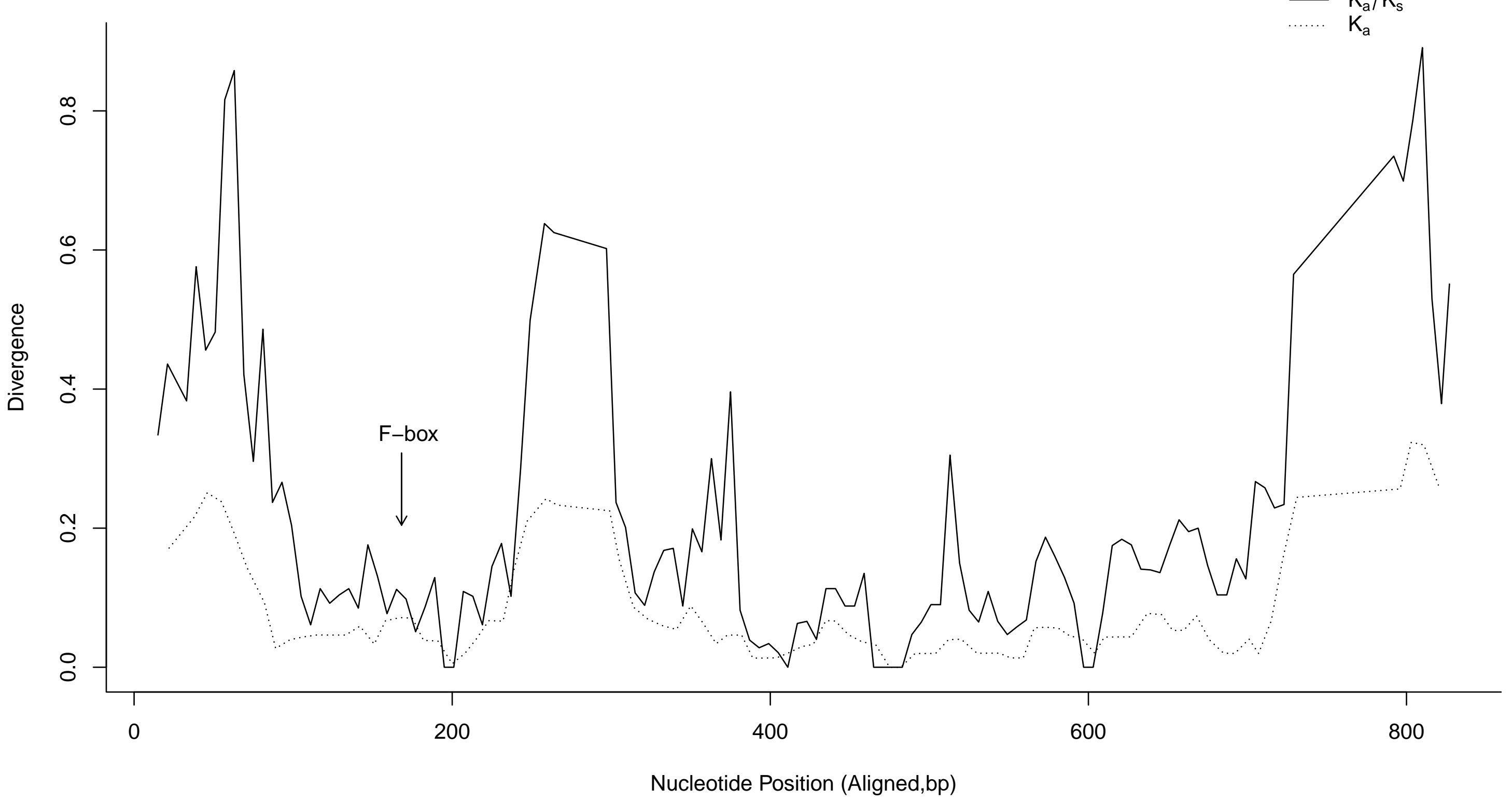




\section{Divergence of Fbxo2}

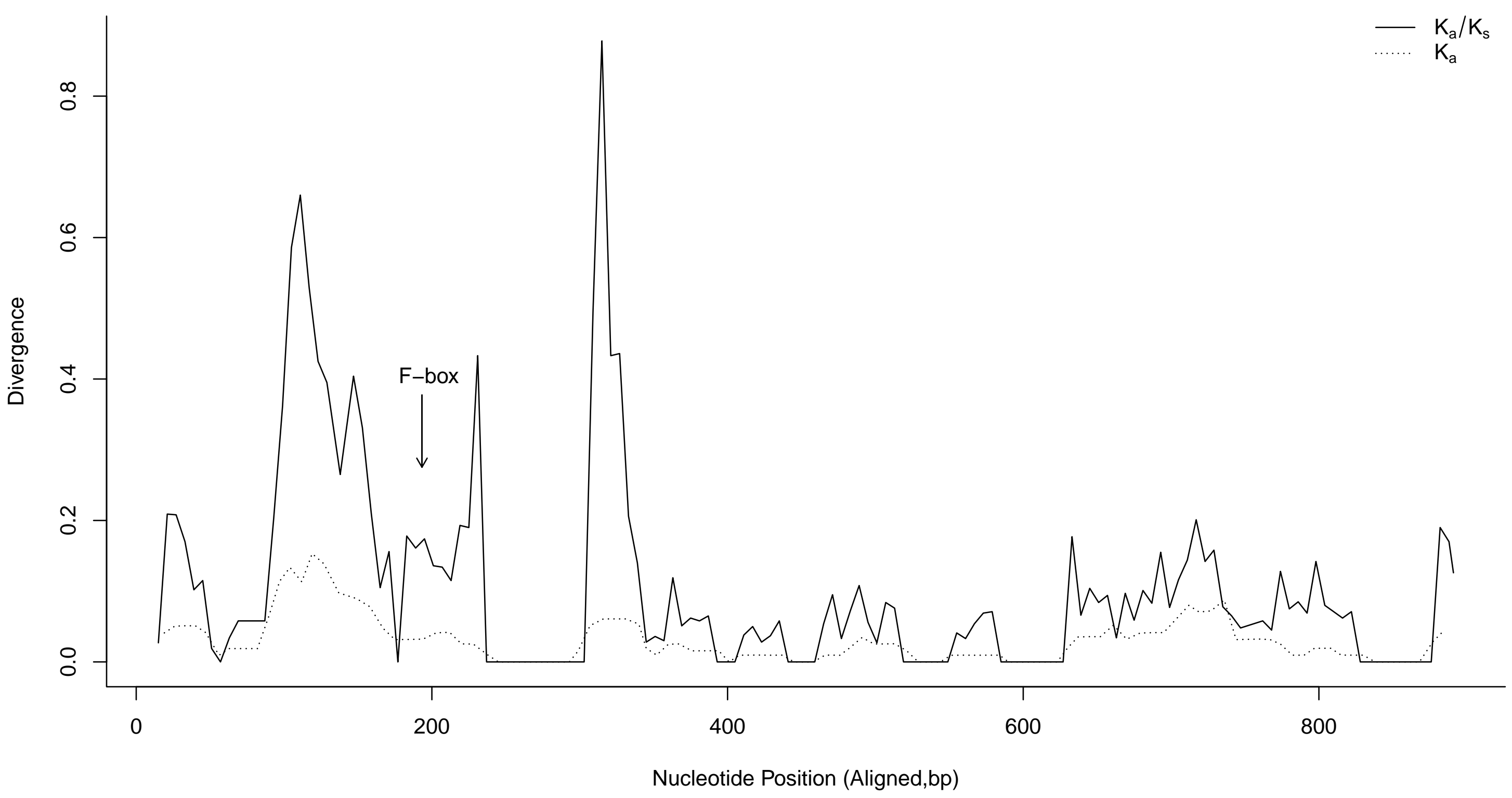




\section{Divergence of Fbxo22}

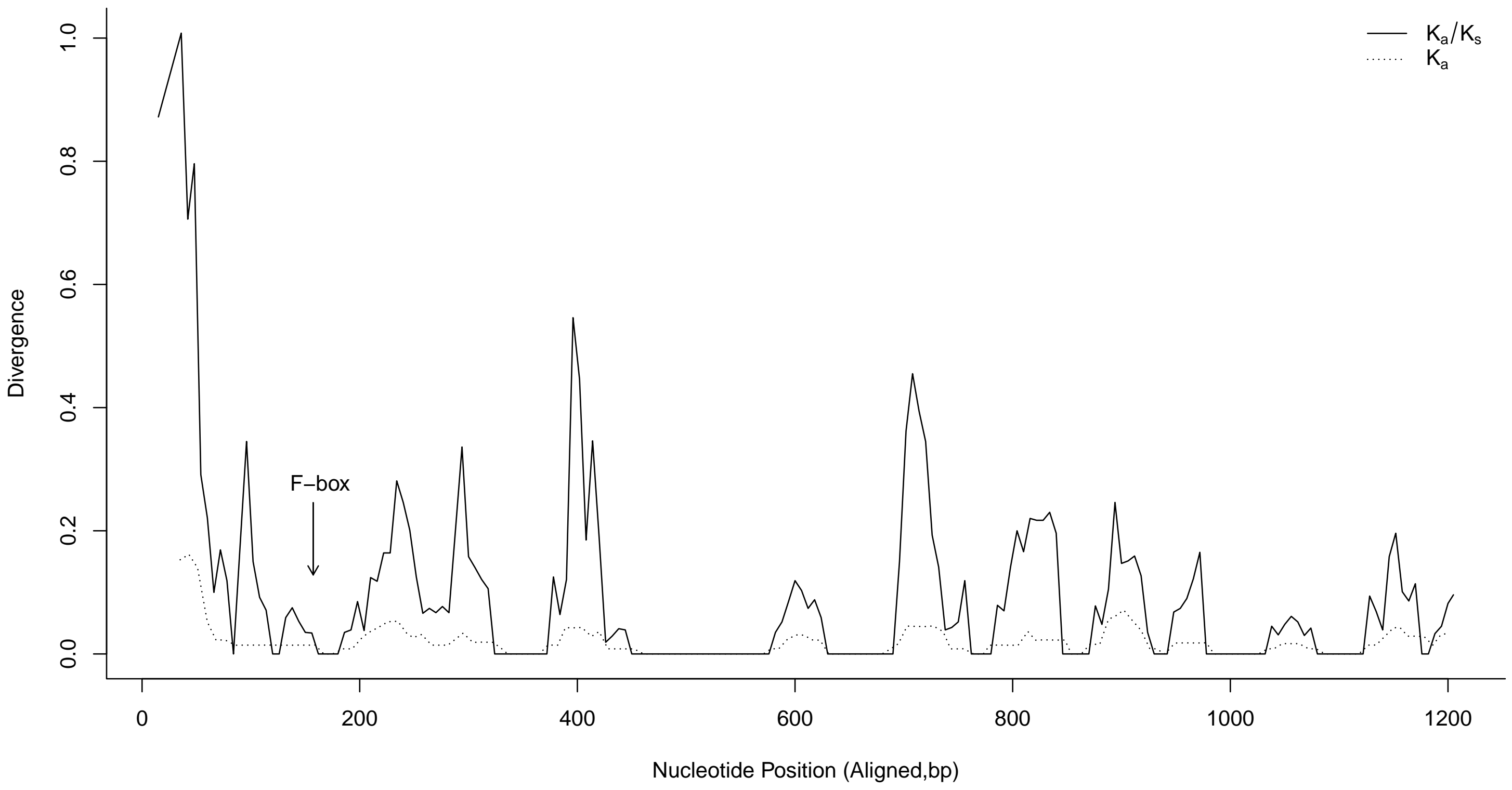




\section{Divergence of Fbxo27}

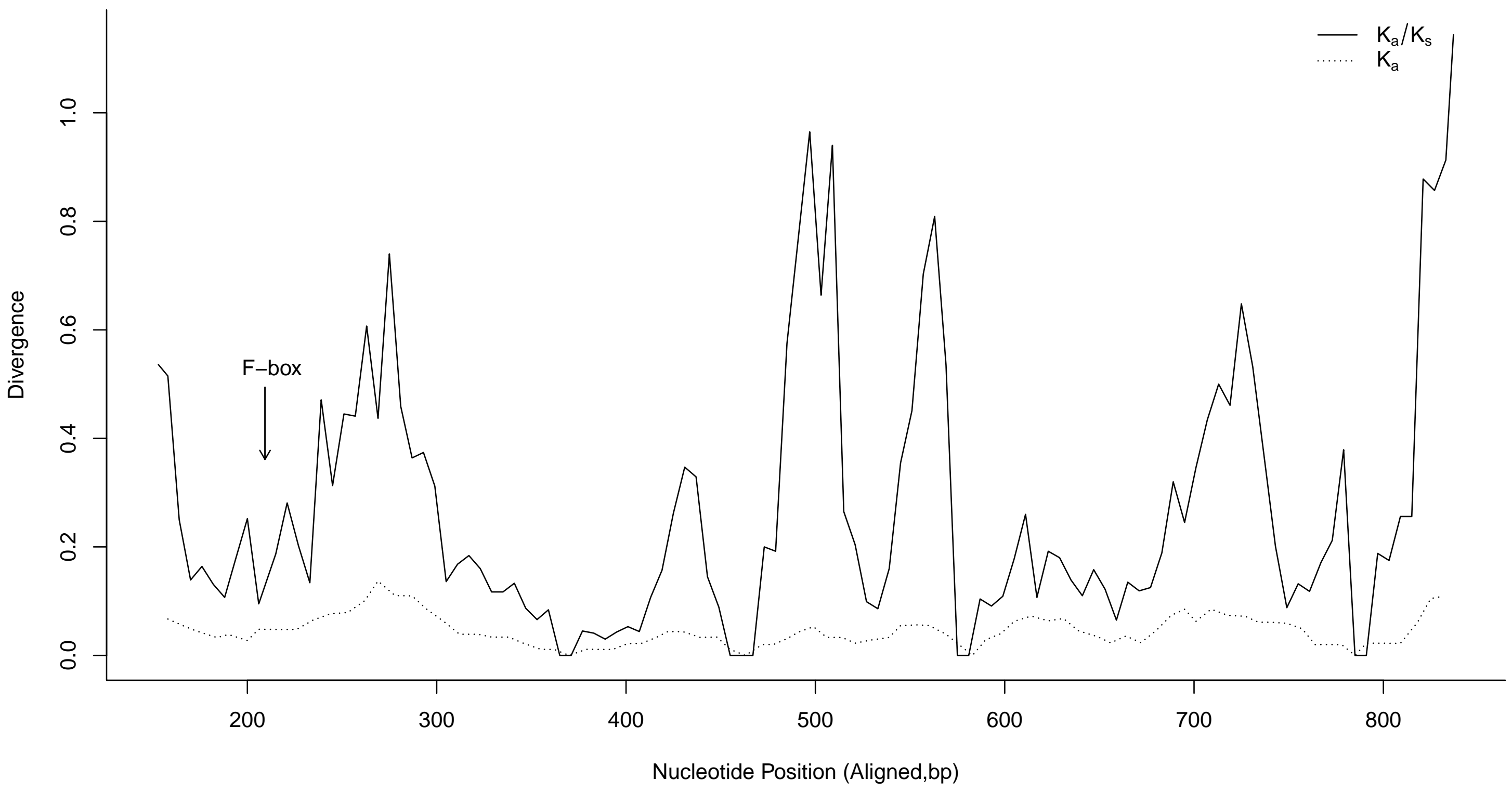




\section{Divergence of $\mathrm{Fbxo3}$}

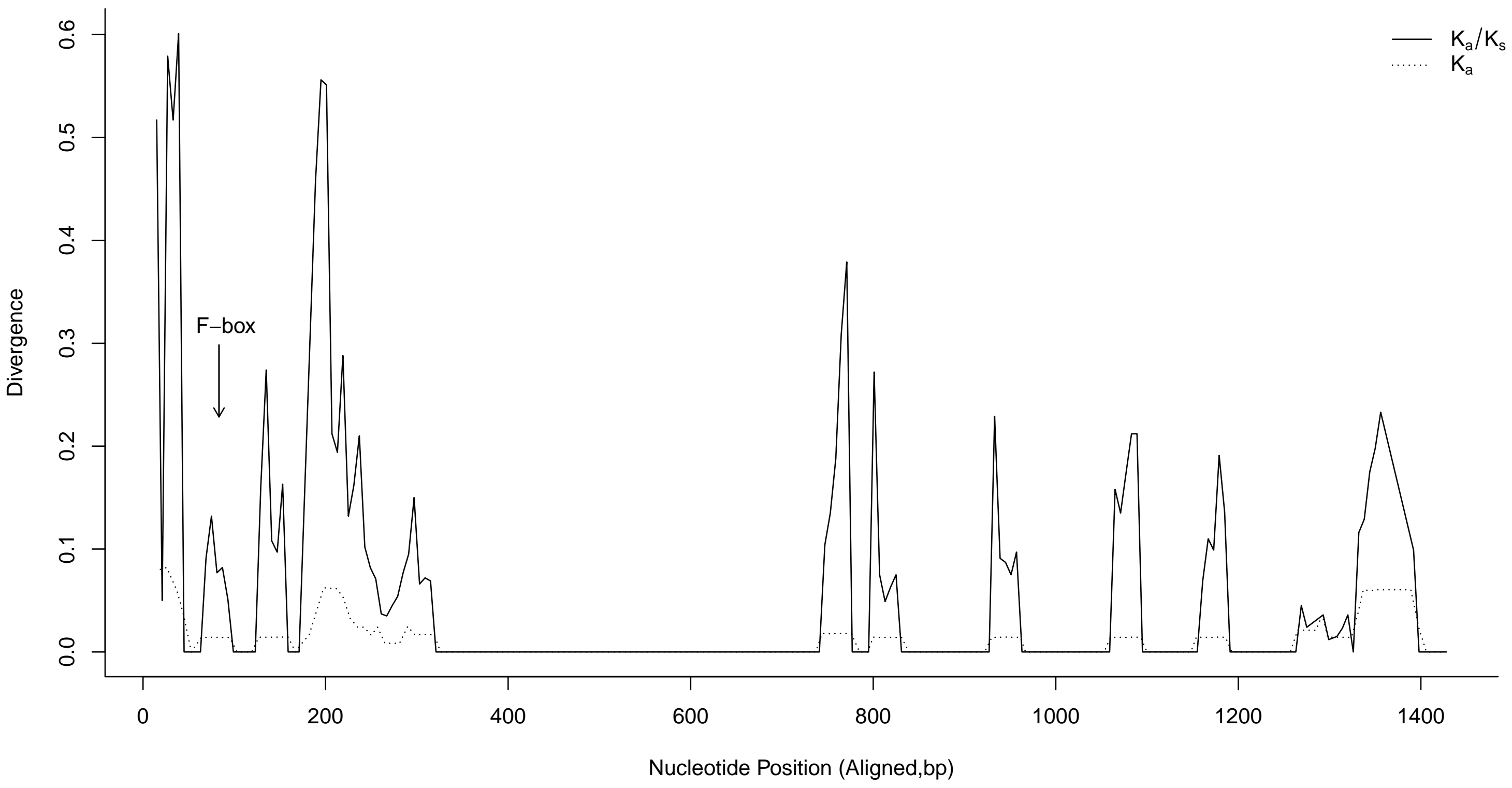




\section{Divergence of Fbxo31}

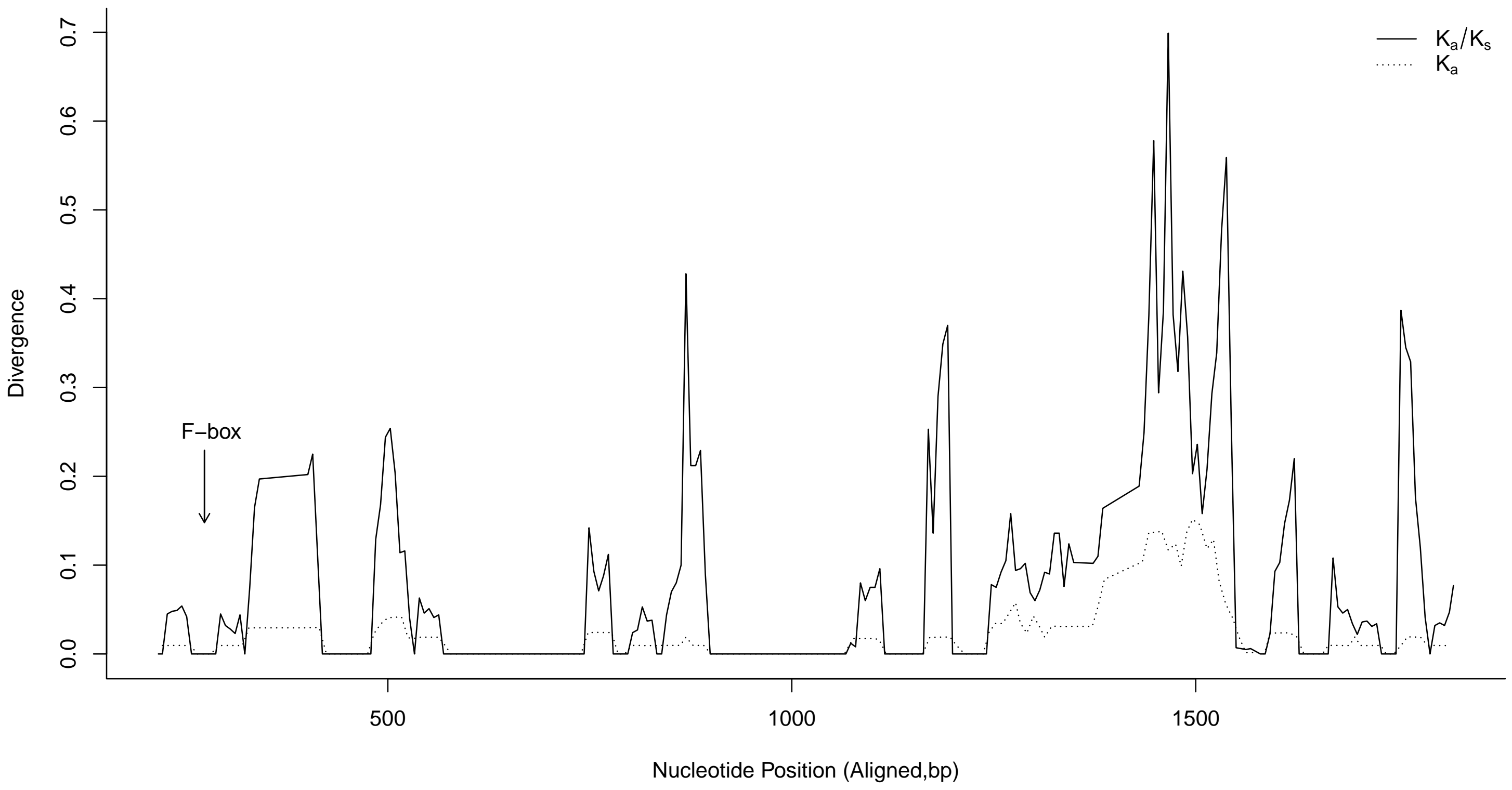


Divergence of Fbxo36

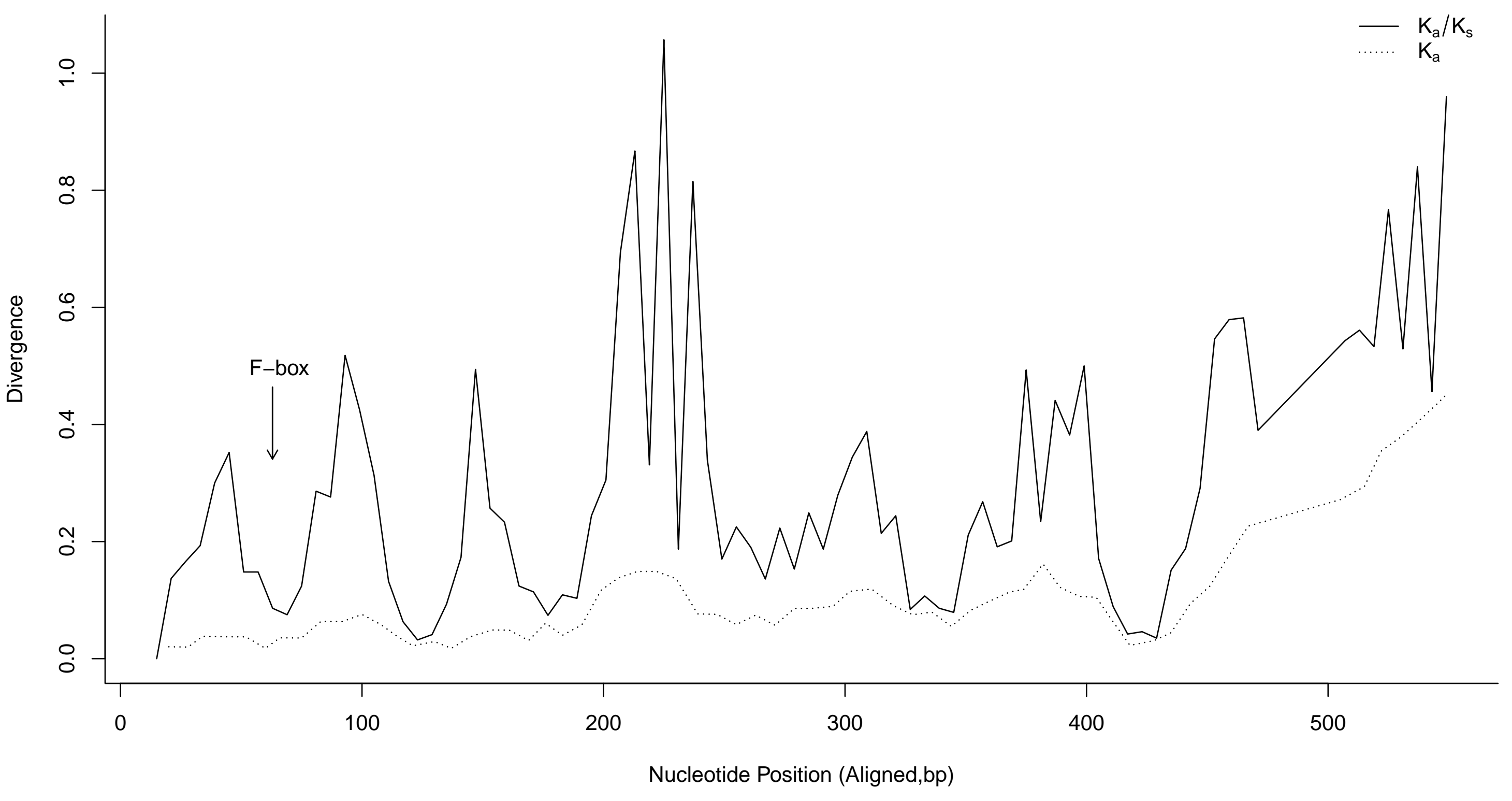




\section{Divergence of Fbxo4}

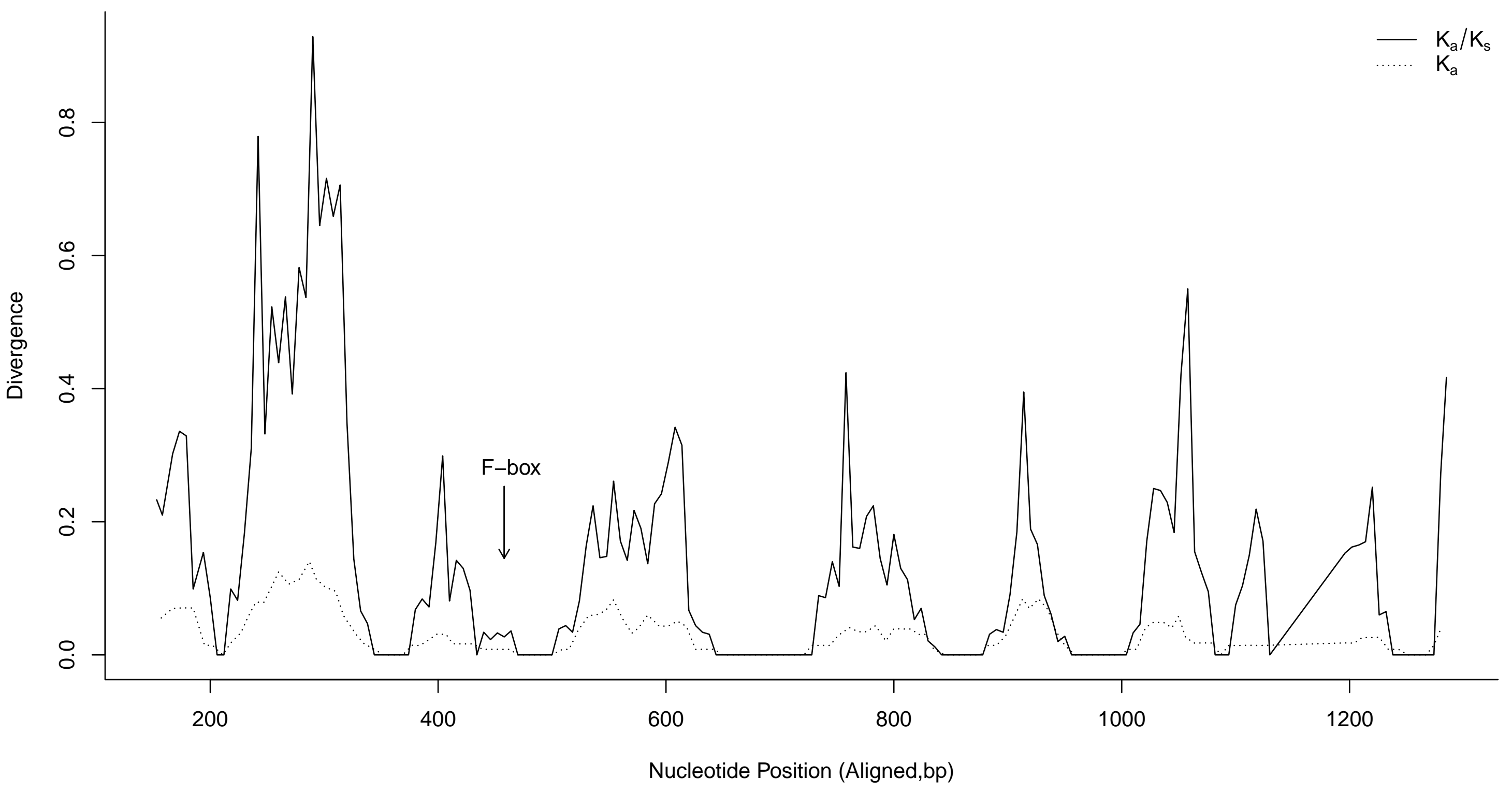




\section{Divergence of Fbxw2}

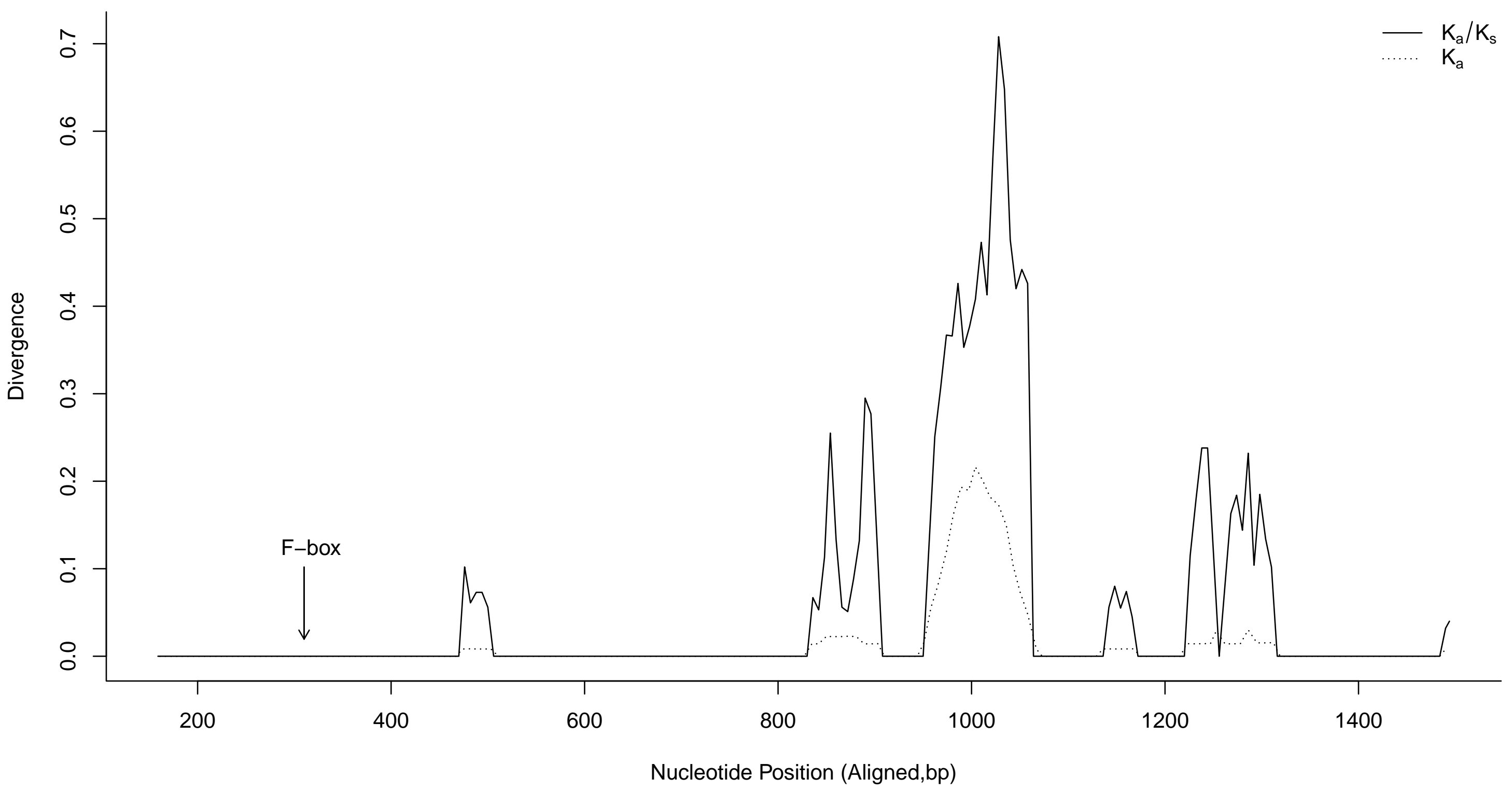




\section{Divergence of Fbxw5}

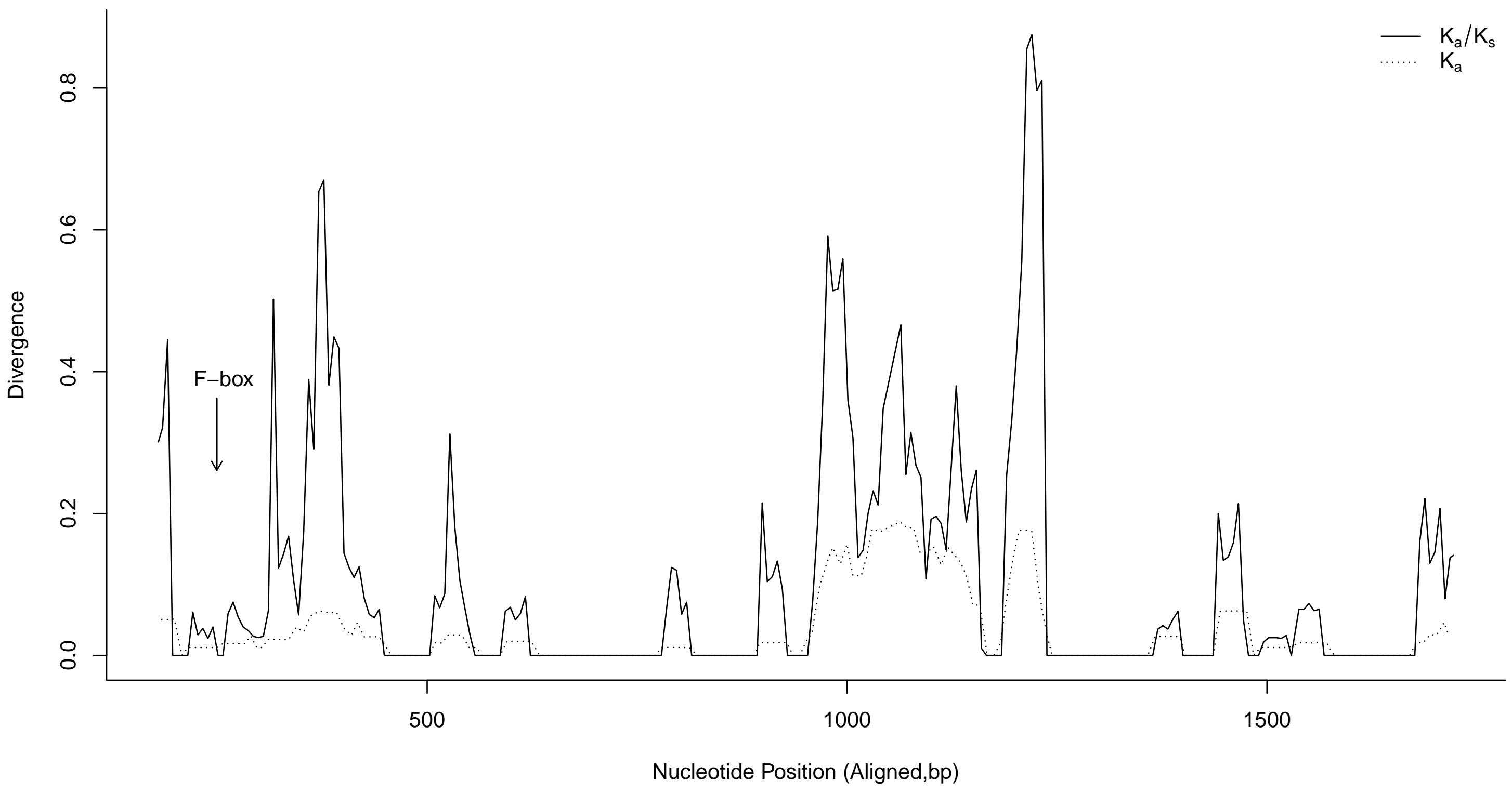




\section{Divergence of Fbxw7}

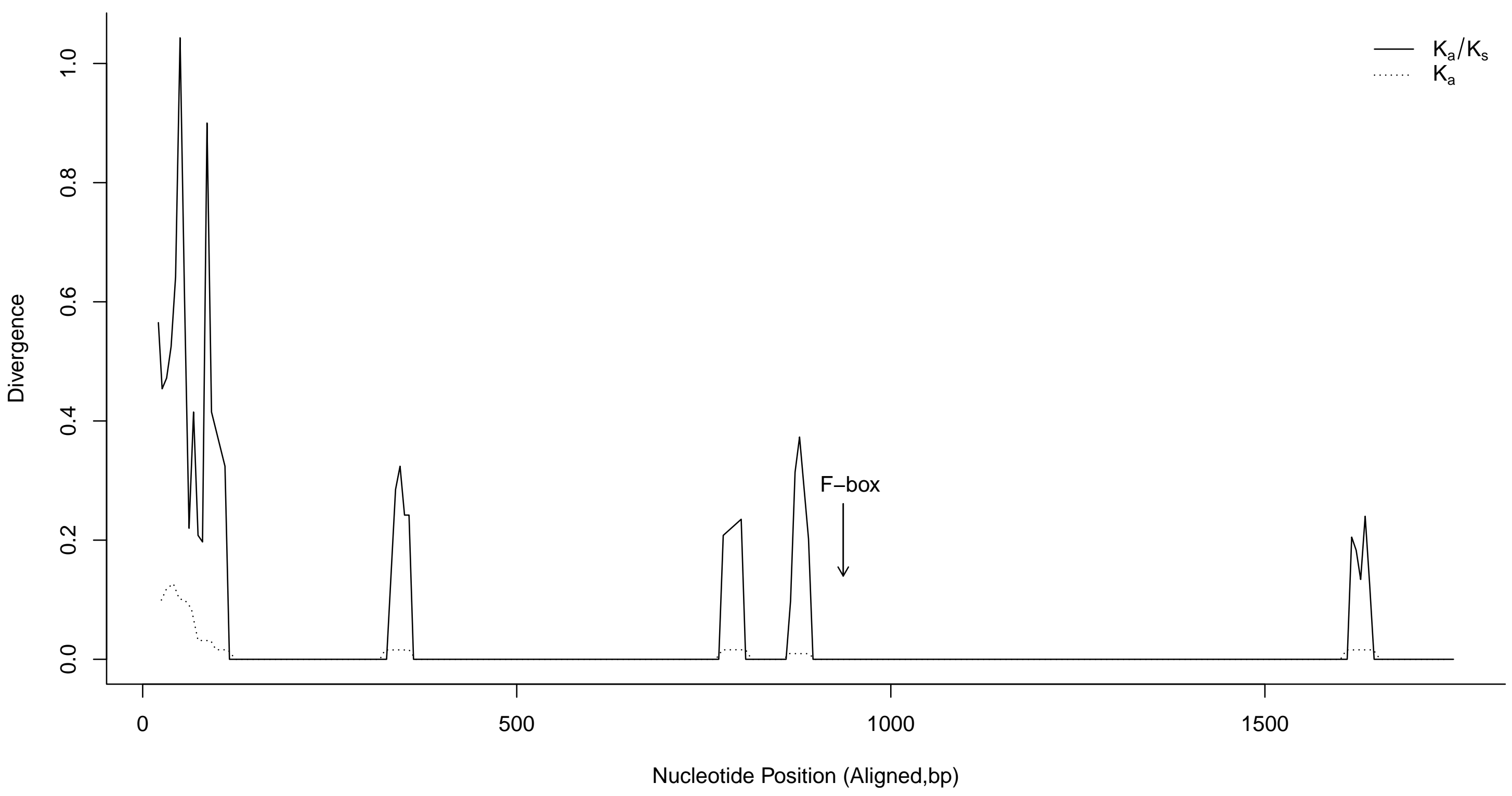




\section{Divergence of Skp2}

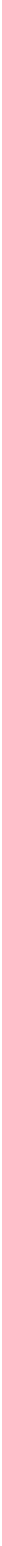

